\title{
CHEMOSPHERE
}

\section{Exposure to the organophosphorus pesticide chlorpyrifos inhibits acetylcholinesterase activity and affects muscular integrity in Xenopus laevis larvae}

\author{
Anita Colombo *, Federica Orsi, Patrizia Bonfanti \\ Dipartimento di Scienze dell'Ambiente e del Territorio, Università degli Studi di Milano Bicocca, \\ Piazza della Scienza 1, I-20126 Milano, Italy
}

Received 3 December 2004; received in revised form 10 March 2005; accepted 6 April 2005

Available online 12 May 2005

\begin{abstract}
The effect of organophosphate pesticide chlorpyrifos (CPF) on acetylcholinesterase (AChE) activity and on skeletal muscle development in Xenopus laevis larvae was studied. To achieve our purpose embryos were exposed to 100, 250 and $3000 \mu \mathrm{g} / \mathrm{l} \mathrm{CPF}$ concentrations from late blastula stage ( $8 \mathrm{~h}$ postfertilization, p.f.) to stage 47 (120 h p.f.) and the appearance of AChE activity was monitored every $24 \mathrm{~h}$. Compared with control, CPF treated larvae showed a dose dependent AChE inhibition during the early stages (beginning from $24 \mathrm{~h}$ until 120 h p.f.) that are crucial for neuromuscular development.

The amount of AChE activity that can still be measured in treated larvae at stage 47 relative to that of the control, ranged from $28 \%$ in CPFs $100 \mu \mathrm{g} / 1$ to $4 \%$ in CPFs $3000 \mu \mathrm{g} / \mathrm{l}$. These low AChE activities were associated with muscular damages such as reduced myotome size and hypertrophies coupled with extensive vacuolated regions in myocytes. The occurrence of this tissue-specific injury was related to CPF concentrations and was most pronounced in CPFs $3000 \mu \mathrm{g} / 1$ which revealed a very severe AChE inhibition during the exposure.

Since AChE is the major neurotransmitter of the neuromuscular system, this initial descriptive study will be an useful starting-point to ongoing and future subcellular/molecular studies that correlate the morphological damage with changes in AChE activity.

(C) 2005 Elsevier Ltd. All rights reserved.
\end{abstract}

Keywords: Chlorpyrifos; Development; Muscle; Acetylcholinesterase inhibitors; Amphibians

\section{Introduction}

Acetylcholinesterase (AChE) is an enzyme characteristic of the insect and vertebrate neuromuscular junctions responsible for the hydrolysis of the neuro-

\footnotetext{
* Corresponding author. Tel.: +3902 6448 2921; fax: +39 02 64482996.

E-mail address: anita.colombo@unimib.it (A. Colombo).
}

transmitter acetylcholine (ACh), so that the activation of cholinergic receptors is transient. Insect AChE is the primary target of organophosphates (OPs) pesticides, which, by phosphorylating the serine hydroxyl group located in the active site of the AChE, inhibit its activity (Ozmen et al., 1999). As a consequence, ACh accumulation in the synapses and neuromuscular junctions leads to overstimulation of cholinergic receptors that results in a general pattern of nerve poisoning worth 
symptoms such as hyperexcitability, tremors and paralysis. The manifestation of cholinergic signs of toxicity in nontarget species exposed to OPs suggests in these organisms a mechanism common to insects. Seasonal use on agricultural fields and intermittent pesticide applications may produce toxic effects affecting different species that are crucial components of many ecological communities, such as amphibians. In the last few years several researches have hypothesized that pesticide applications are a potential cause of amphibian decline (Wake, 1991; Blaustein and Wake, 1995). Amphibians are particularly vulnerable to these compounds for various reasons: they breed and lay eggs in spring when great quantities of pesticides are applied in agriculture, tadpole skin is highly permeable to toxic substances and metamorphosis represents a critical step during larval development that can be disrupted by exogenous compounds.

Although a link between use of pesticides and amphibian population decline has not yet been established, there is experimental evidence demonstrating that exposure to pesticides may be harmful to embryo development (Lien et al., 1997; Harris et al., 1998; Gillilland et al., 2001; Karen et al., 2001; Sahu and Ghatak, 2002).

OPs elicit severe malformations ascribed as abnormal tail flexure, contorted posture and abnormal notochord in various species of frog embryos. In previous studies, the same malformations were observed in association with a serious impairment of motility in OP treated Xenopus laevis larvae, a well-known amphibian experimental model (Snawder and Chambers, 1989, 1990, 1993; Richards and Kendall, 2002, 2003; Bonfanti et al., 2004).

In view of these alterations, a deeper investigation into OPs effects other than the well known AChE inhibition was needed. Damage to skeletal muscle for instance could result in motionless larvae unable to forage or escape predation in the environment.

Since literature data (Behra et al., 2002) reveal that the maintenance of muscle cell integrity in zebrafish clearly depends on AChE activity, in the present work we investigated the extent to which chlorpyrifos $(O, O$ diethyl $O$-[3,5,6-trichloro-2-pyridyl] phosphorothioate) $(\mathrm{CPF})$, one of the most used OPs (Barron and Woodburn, 1995; Lemus and Abdelghani, 2000), inhibited AChE activity during the nervous and muscular system development in $X$. laevis and how the axial muscular integrity could be damaged.

For this purpose exposure to $\operatorname{CPF}(100,250$ and $3000 \mu \mathrm{g} / \mathrm{l})$ was carried out from late blastula stage $(8 \mathrm{~h}$ postfertilization, p.f.) to stage 47 (120 h p.f.). During the exposure time AChE activity was monitored every $24 \mathrm{~h}$ because of rapid changes of AChE activity in the first $120 \mathrm{~h}$ of development and morphological analysis was carried out at histological and ultrastructural level in 47 stage larvae, when the myogenesis process has led to myofibril filled myotubes.

\section{Materials and methods}

\subsection{Chemicals}

The organophosphorus insecticide chlorpyrifos ( $O, O$-diethyl $O$-[3,5,6-trichloro-2-pyridyl] phosphorothioate; CPF) with over $99 \%$ purity was supplied by Labservice Analytica s.r.1., Italy. The reagents for morphological analysis were purchased by Trimital s.r.l., Italy. All analytical grade reagents were obtained from Sigma-Aldrich s.r.1., Italy.

\subsection{In vitro fertilization and embryo treatment}

Xenopus laevis adult males and females were purchased from the Centre d'élevage de Xénopes du CNRS, Rennes, France. The animals were acclimated for at least six weeks in aquaria with dechlorinated tap water at temperature of $22 \pm 2{ }^{\circ} \mathrm{C}$ and alternating $12 \mathrm{~h}$ light/ dark cycles and fed a semi-synthetic diet (Mucedola s.r.1., Settimo Milanese, Italy).

In vitro fertilization was performed as previously reported (Vismara et al., 1993). Briefly, females were induced to ovulate by human chorionic gonadotropin injection. Freshly extruded eggs were inseminated in vitro with a testicular homogenate and after $1 \mathrm{~min}$ FETAX solution (Dawson and Bantle, 1987) was added to each Petri dish.

Three groups of 156 embryos each were exposed to CPF (100, 250 and $3000 \mu \mathrm{g} / \mathrm{l}$ in FETAX solution) and one group was untreated and used as control. All test solutions were administered $8 \mathrm{~h}$ p.f. until $120 \mathrm{~h}$ p.f., and embryos were kept in a thermostatic chamber at $23 \pm 0.5^{\circ} \mathrm{C}$; each day the test and control solutions were renewed.

For each experimental group, AChE evaluation was performed on three pools of 10 embryos, sacrificed every $24 \mathrm{~h}$ until stage 47 (120 h p.f.) whereas morphological analysis was carried out on six embryos at $120 \mathrm{~h}$ p.f. All the experiments were repeated three times and the embryo pools were always randomly sampled.

\subsection{AChE activity analysis}

Control and CPF exposed pools were used for AChE evaluation. Each assay was performed in triplicate using a modified Ellman procedure (Ellman et al., 1961) with acetylthiocholine iodide $(0.075 \mathrm{M})$ as a substrate. The Ellman protocol was adapted to quantify AChE activity in X. laevis embryos (Gindi and Knowland, 1979).

Briefly, after being repeatedly rinsed in dechlorinated tap water, whole body embryos were chilled on ice and homogenized in Tris buffer $(1 \%$ Triton $\mathrm{X}-100$ in $0.05 \mathrm{M}$ Tris- $\mathrm{HCl}, \mathrm{pH} 7.4)$ at 1:10 (w/v) and centrifuged for $5 \mathrm{~min}$ at $15000 \mathrm{~g}$. The presence of thiol groups masks low levels of AChE causing an incorrect evaluation of 
enzyme activity. For this reason, before adding the substrate, a pre-incubation of the extracts with $0.33 \mathrm{mM}$ 5,5'-dithio-bis (2-nitrobenzoic acid) for $10 \mathrm{~min}$ was necessary. The absorbance changes were followed every $15 \mathrm{~s}$ for at least $15 \mathrm{~min}$ at $412 \mathrm{~nm}$.

Preliminary experiments were conducted to define conditions for sample concentration required for linear rates of substrate hydrolysis. AChE activity was calculated as nmol of acetylthiocholine iodide hydrolyzed per min per $\mathrm{g}$ embryos.

Statistical analysis was performed using the program STATGRAPHICS PLUS, version 5.1. Data sets that were normally distributed and possessed equal variances were analyzed using a multifactor analysis of variance (ANOVA) to determine if there were significant $(P \leqslant$ $0.05)$ differences among treatments, with respect to AChE activities. Tukey's method was used to determine if significantly different AChE activities existed among the different factors: CPF concentrations and time points; Dunnett's method was used to determine which treatments were significantly different from the control.

\subsection{Morphological studies}

Stage 47 (120 h p.f.) control and exposed larvae were fixed for $2 \mathrm{~h}$ in modified Karnowsky's liquid ( $2 \%$ paraformaldehyde, $0.2 \%$ glutaraldehyde in $0.1 \mathrm{M}$ phosphate buffer, $\mathrm{pH}$ 7.4), repeatedly rinsed in the same buffer and postfixed for $2 \mathrm{~h}$ in $1 \% \mathrm{OsO}_{4}$ in phosphate buffer, $\mathrm{pH}$ 7.4. Following rinsing in $0.1 \mathrm{M}$ phosphate buffer, the materials were dehydrated in graded alcohol series and embedded in epoxy resin Epon 812. The Epon blocks were cut on an LKB ultramicrotome. Longitudinal semi thin sections $(0.5 \mu \mathrm{m})$ were stained with crystal violet and basic fuchsin and examined under a light Zeiss Axioplan MC 100 microscope. Images were taken by a colour digital camera (Image Pro Plus version 4.5.1, Media
Cybernetics). Ultrathin sections were contrasted with uranil acetate and lead citrate according to the standard Reynolds method (Reynolds, 1963), and examined in a TEM Jeol JEM 1220 at an accelerating voltage of $80 \mathrm{kV}$.

\section{Results}

\subsection{AChE activity}

The effect of CPF on AChE activity was monitored every $24 \mathrm{~h}$ in developing embryos during the exposure time. In control no enzyme activity was found at $24 \mathrm{~h}$ p.f. A consistent increase was seen starting from $48 \mathrm{~h}$ up to 120 h p.f. (Fig. 1), in relation to the development of the nervous and muscular system. The exposure to CPF elicited an inhibition of AChE activity in each treated group and this residual activity was statistically different from control activity starting from 72 h p.f. (Fig. 1). Moreover, the residual AChE activity remained almost unvaried during the stages of development studied. At the end of exposure (stage 47, $120 \mathrm{~h}$ p.f.) the enzyme inhibition ranged from $72 \%$ at $100 \mu \mathrm{g} / 1$ to $96 \%$ at $3000 \mu \mathrm{g} / 1$ in comparison with the control. The AChE mean activities at $3000 \mu \mathrm{g} / \mathrm{l}$ were statistically different from those at $100 \mu \mathrm{g} / 1$ starting from $72 \mathrm{~h}$ p.f.

\subsection{Morphological analysis}

On gross morphological analysis the all treated larvae ( $n=18$ for each treatment group) showed impairment of motility, such as tremors and spasms and, at the highest concentration, paralysis compromising larvae swimming ability. In particular the impairment of motility was associated with physical abnormalities, ascribing to an abnormal tail flexure (Fig. 2B), in six out of 18 larvae in CPFs $100 \mu \mathrm{g} / \mathrm{l}$, in 12 out of 18 larvae in CPFs $250 \mu \mathrm{g} / \mathrm{l}$ and in 18 out of 18 larvae in CPFs $3000 \mu \mathrm{g} / \mathrm{l}$.

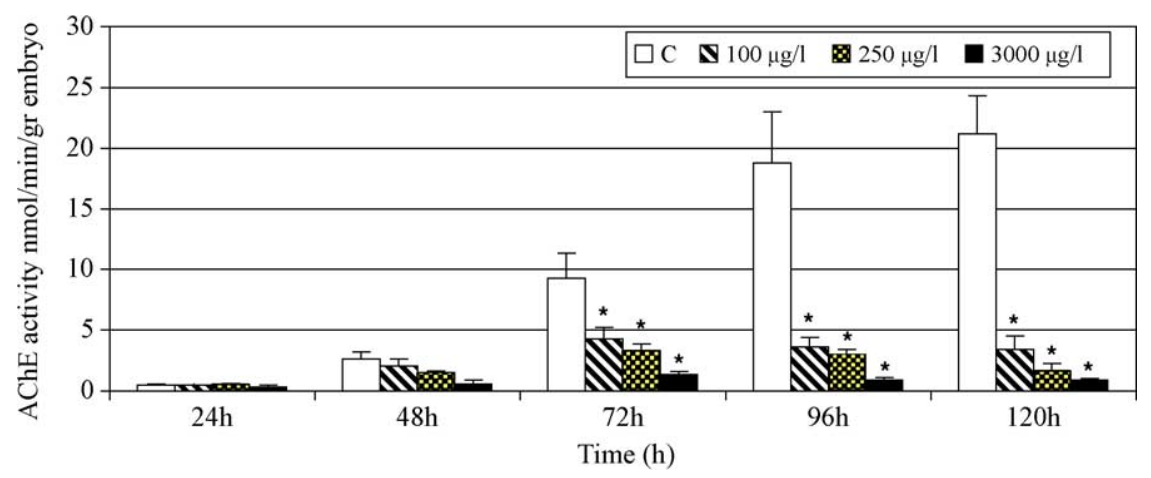

Fig. 1. AChE activity in X. laevis larvae control and exposed to CPF 100, 250 and $3000 \mu \mathrm{g} / \mathrm{l}$. Each value represents the mean \pm SD obtained from three independent assays carried out in triplicate on three pools of larvae. Asterisk indicates statistically significant difference from control $(P<0.05)$. 

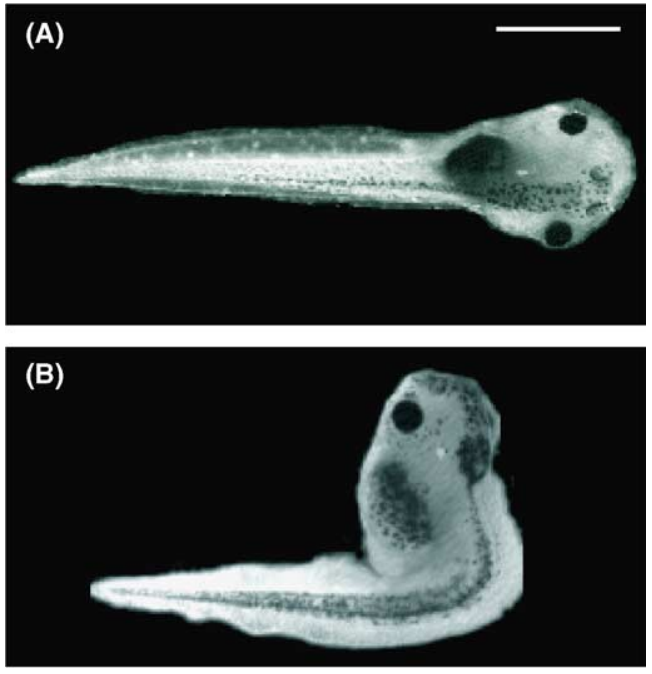

Fig. 2. Stage 47 (120 h p.f.) X. laevis larvae. Dorsal view of control larva (A) and abnormal tail flexure of larva exposed to $3000 \mu \mathrm{g} / \mathrm{l} \mathrm{CPF}$ (B). Scale bar $=3 \mathrm{~mm}$ for A and B.

\subsection{Histological studies}

Longitudinal tail tissue sections, obtained from larvae at $120 \mathrm{~h}$ p.f., were analyzed from control and each treatment group $(n=18)$. The control tails showed a reg- ular myotomal structure defined by intersomitic boundaries to which myocytes, oriented in parallel to the notochord, are anchored (Fig. 3A). In each myotome the regular arrangement of striated muscle was evident with succession of A and I bands.

After exposure to CPF, the tail musculature revealed a reduction in myotomal length and alteration in its structure (Fig. 3B-D) due to the appearance of extracellular spaces between myocytes and vacuolated regions. Moreover, the myocytes revealed a disorganization of the contractile apparatus with the presence of hypertrophied areas. These alterations of tail muscle structure increased in a dose dependent manner in all three independent trials. Indeed, the damage, limited in CPFs $100 \mu \mathrm{g} / 1$ (Fig. 3B), was more extensive in CPFs $250 \mu \mathrm{g} / \mathrm{l}$ where myotomal boundaries were undefined (Fig. 3C), whereas in CPFs $3000 \mu \mathrm{g} / \mathrm{l}$ the myotomal structure was completely destroyed and the muscle fibres entirely degenerated (Fig. 3D). In particular in the bent region of CPFs $100 \mu \mathrm{g} / \mathrm{l}$ and $250 \mu \mathrm{g} / \mathrm{l}$ the myotome disorganization was more severe than in nonbent areas.

\subsection{Ultrastructural studies}

A preliminary analysis of ultrastructural morphology was performed on control larvae and exposed to $3000 \mu \mathrm{g} / \mathrm{l} \mathrm{CPF}$ with the attempt to visualize to a greater detail the vacuolated areas. In longitudinal control sec-
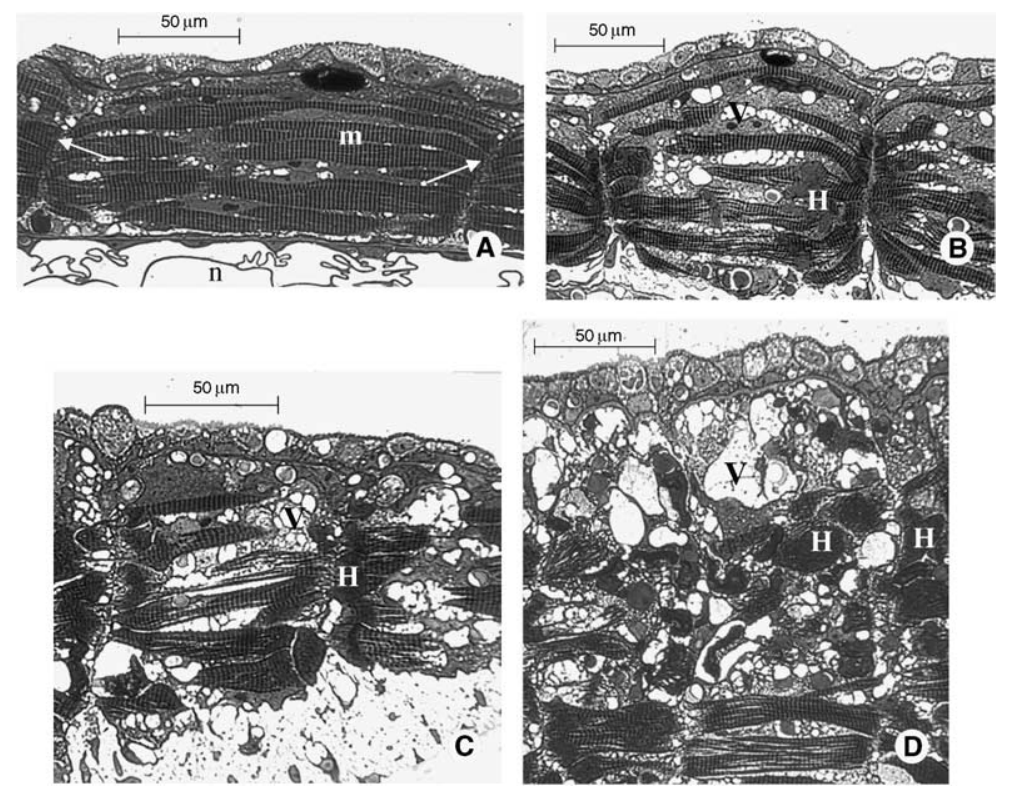

Fig. 3. Histological analysis of tail muscle in control and CPF treated X. laevis larvae at stage 47 (120 h p.f.). Myotomes of control larva showed contiguous muscle cells $(\mathrm{m})$ across myotomal boundaries (white arrow) oriented in parallel to the notochord (n) (A). Treatment with $100 \mu \mathrm{g} / \mathrm{l}$ (B), $250 \mu \mathrm{g} / \mathrm{l}$ (C) and $3000 \mu \mathrm{g} / \mathrm{l}$ (D) of CPF caused an increasing disorganisation of muscle cells by the appearance of vacuolated $(\mathrm{V})$ and hypertrophied $(\mathrm{H})$ regions leading to the loss of intersomitic boundaries in the bent tail region. Scale bar $=50 \mu \mathrm{m}$ for $\mathrm{A}, \mathrm{B}, \mathrm{C}$ and $\mathrm{D}$. 

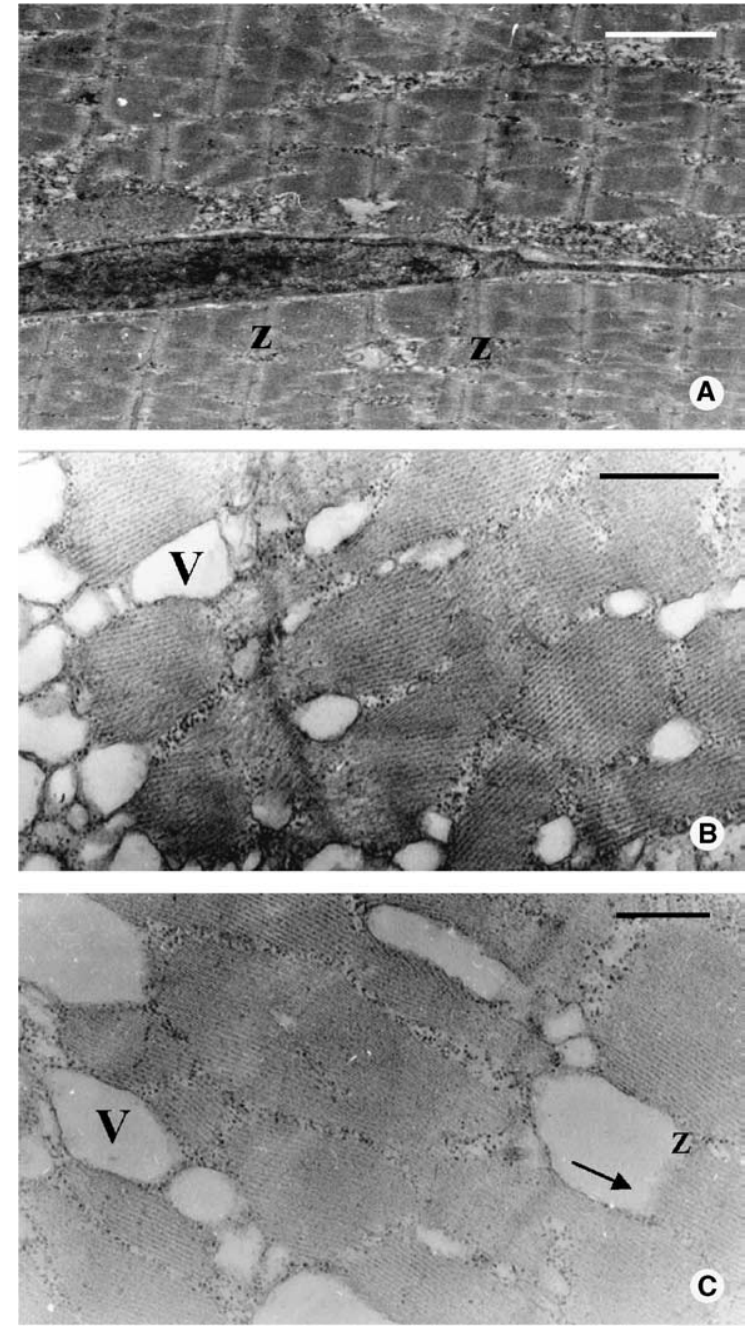

Fig. 4. Ultrastructural morphology of tail muscle in control and $3000 \mu \mathrm{g} / \mathrm{l} \mathrm{CPF} X$. laevis larvae at stage 47 (120 h p.f.). Longitudinal section of striated muscle in control larvae showed a regular disposition of sarcomeres (A) $(\times 3000$, scale bar $=3 \mu \mathrm{m})$. Thin sections of CPFs treated showed the presence of vacuolated regions (V) among the myofibrils (B) $(\times 15000$, scale bar $=0.6 \mu \mathrm{m})$ and the break down of myofilaments (black arrow) from Z-disk (z) $(C)(\times 20000$, scale bar $=$ $0.4 \mu \mathrm{m})$.

tions, myocytes exhibited a repeating array of sarcomeres well defined by Z-disks (Fig. 4A). In contrast, the CPF larvae showed extensive regions of vacuolated sarcoplasm interrupting the regular myofibril arrangement (Fig. 4B), although it was hard to make longitudinal sections in the bent tail regions. The morphology of the vacuolated region at high magnification suggested a break down of myofilaments from Z-disk due to the lost of their connection with the Z-disk protein complex (Fig. 4C).

\section{Discussion}

Many literature data evidenced that OPs elicit AChE inhibition and morphological alterations such as notochordal sheath defects in amphibians (Snawder and Chambers, 1993; Richards and Kendall, 2002, 2003). Our study concerning the effects of the commonly used insecticide $\mathrm{CPF}$ on $X$. laevis larvae produced two major findings. First, exposure of embryos to CPF from blastula stage ( 8 h p.f.) until stage 47 (120 h p.f.) inhibited AChE activity in a dose-dependent manner. Second, a morphological inspection of larvae at $120 \mathrm{~h}$ p.f. revealed dose-dependent, tissue-specific damage in the tail musculature, besides the notochordal sheath alteration, which was unknown in nonmammalian vertebrates.

OPs and CPF in particular are heavily used in agriculture and in households because they have replaced the more persistent organochlorine pesticides. Theoretically they should not accumulate in the environment, but unexpectedly high concentrations of CPF in remote areas far from utilization site were found (Chernyak et al., 1996; Garbarino et al., 2002; Muir et al., 2004). This fact increased the importance to add investigations on potential risk deriving from CFP exposure.

The tested concentrations (100, 250 and $3000 \mu \mathrm{g} / \mathrm{l})$ were experimental ones and were higher than those found in the environment and than $\mathrm{LC}_{50}$ values reported for crustacean and insect larvae $(<1 \mu \mathrm{g} / \mathrm{l})$ and for fish (1-100 $\mu \mathrm{g} / 1)$ (Barron and Woodburn, 1995); however these concentrations were chosen in order to obtain histological information that may serve as the first descriptive step in determining the molecular mechanisms underlying the effect of AChE inhibition caused by $\mathrm{CPF}$ on muscle damage.

The rapid development of the neuromuscular system in Xenopus (Seidman et al., 1994) makes it an excellent in vivo model to study OP toxicity and to identify xenobiotics that cause muscular disorders.

In control embryos, the development and ultrastructural maturation of the neuromuscular system give rise to a free swimming tadpole within 4-5 days. Concurrently, in our results quantifiable levels of AChE activity first appeared from 24 to $48 \mathrm{~h}$ p.f., and this activity increased with each progressive stage of outgrowth according to Gindi and Knowland (1979).

AChE inhibition in CPF treated larvae proved to be dose-dependent and in contrast to the control, the still measurable AChE activity in CPF treated groups stabilized at values not much higher than those measured at $48 \mathrm{~h}$ during the exposure time. This underlines the fact that AChE activities were very low, compared with the controls, during a crucial period for neuromuscular development.

AChE residual activities in larvae at stage 47, ranging from $28 \%$ in CPFs $100 \mu \mathrm{g} / 1$ to $4 \%$ in CPFs $3000 \mu \mathrm{g} / \mathrm{l}$ in comparison with the control, were associated with 
muscular damage. The occurrence of this tissue-specific injury was related to $\mathrm{CPF}$ concentrations and was most pronounced in CPFs $3000 \mu \mathrm{g} / 1$, which revealed a most severe AChE inhibition during the exposure. In our histological studies a severe histopathological damage, such as reduced myotome size and hypertrophies coupled with extensive vacuolated regions in myocytes, was observed in CPFs $3000 \mu \mathrm{g} / \mathrm{l}$. According to CPF teratogenic concentration value in $50 \%$ of larvae $\left(\mathrm{TC}_{50}=\right.$ $161.54 \mu \mathrm{g} / \mathrm{l}$ ) found in our previous teratogenesis assay (Bonfanti et al., 2004), tail flexure did not occur in all larvae exposed to CPF 100 and $250 \mu \mathrm{g} / \mathrm{l}$, whereas it appeared in $100 \%$ of the larvae exposed at the highest concentration. Although more severe muscular abnormalities were evidenced in the bent tail region, an initial muscle disorganization was found by histological analysis in all bent and nonbent larvae exposed to lower $\mathrm{CPF}$ concentrations.

Other authors have found a quantitative relation between AChE levels and skeletal muscle necrosis in OP treated rats, suggesting that the loss of AChE activity could be the trigger mechanism leading to muscular degeneration (Gupta et al., 1987; De Bleecker et al., 1994). Behra et al. (2002) reported that a mutation in zebrafish ache caused impairment of motility and severe muscular system defects during early larval stages similar to those observed by us in $X$. laevis exposed to CPF. According to literature data we hypothesize that the inhibition of $\mathrm{AChE}$, elicited by the pesticide, is involved in the appearance of muscle damage in CPF treated larvae.

Some authors ascribed the musculature impairment in OP treated adult mammals to an excessive calcium influx caused by $\mathrm{ACh}$ accumulation and subsequent overstimulation of the postsynaptic membrane (Wecker et al., 1986; De Bleecker et al., 1994). The involvement of calcium as the mediator of muscle necrosis has been described by Leonard and Salpeter (1979) who related the myocyte disorganization to $\mathrm{Ca}^{2+}$-activated proteases which specifically disarray Z-disks in mammalian skeletal muscles. In zebrafish ache mutant embryos muscular degeneration was evident starting from 48 h p.f. when increasing and focalized muscle stimulation lead to accumulation of $\mathrm{ACh}$ in the synapse and constant occupancy of ACh receptors (Behra et al., 2002).

The loss of characteristic striation and the presence of wide areas with frayed myofibrils, observed in malformed tail regions of Xenopus larvae, are in agreement with the above hypothesis. The marked hypertrophies present in myocytes suggest an aggregation of broken myofibrils and a perturbation of the contractile apparatus. The myofibril organization at ultrastructural level in CPFs $3000 \mu \mathrm{g} / \mathrm{l}$ was altered by the presence of vacuolated areas. These areas seemed to be deprived of myofilaments suggesting the loss of a mechanical link between actin filaments and Z-disk proteins, such as $\alpha$ actinin, or the costameric proteins and the extracellular matrix. The perturbations in the connectivity due to disorganization or proteolysis of protein complexes, involved in the highly ordered sarcomeric structure, could be why CPF induced muscle degeneration. Indeed, similar myocyte ultrastructural alterations are expressed in pathologies where specific proteins involved in sarcomeric structure are modified. The genetic alterations in dystrophin lead, for instance, to muscle fragility, contraction-induced damage and necrosis (Spence et al., 2002). A concomitant perturbation of collagen synthesis (Snawder and Chambers, 1993), could be another factor contributing in the alteration of muscular tissue architecture as well as in the loss of intersomitic boundaries.

In conclusion, to the best of our knowledge the results obtained indicate for the first time the CPF dose-dependent effect on the tail muscle apparatus during the development of anuran larvae.

Although no literature data exist about CPF effects on adult Xenopus musculature, the experimental evidences described in adult mammals (Wecker et al., 1986; De Bleecker et al., 1994) suggest that the link between muscular damage and AChE inhibition could be displayed not only during development but in adult animals as well. Moreover a different potential risk could be noticed within amphibian species in relation to their wide range of sensitivity to CPF (Barron and Woodburn, 1995).

Nevertheless, further studies concerning subcellular/ molecular mechanisms are called for to clarify the relationship between the AChE inhibition and muscular damage.

\section{Acknowledgment}

This work was founded by Grant FAR 2003 to A.C.

\section{References}

Barron, M.G., Woodburn, K.B., 1995. Ecotoxicology of chlorpyrifos. Rev. Environ. Contam. Toxicol. 144, 1-93.

Behra, M., Cousin, X., Bertrand, C., Vonesch, J.-L., Biellmann, D., Chatonnet, A., Strähle, U., 2002. Acetylcholinesterase is required for neuronal and muscular development in the zebrafish embryo. Nat. Neurosci. 5 (2), 111-118.

Blaustein, A.R., Wake, D.B., 1995. The puzzle of declining amphibian populations. Sci. Am. 272 (4), 52-57.

Bonfanti, P., Colombo, A., Orsi, F., Nizzetto, I., Andrioletti, M., Bacchetta, R., Mantecca, P., Fascio, U., Vailati, G., Vismara, C., 2004. Comparative teratogenicity of chlorpyrifos and Malathion on Xenopus laevis development. Aquat. Toxicol. 70 (3), 189-200.

Chernyak, S.M., Rice, C.P., McConnell, L.L., 1996. Evidence of currently-used pesticides in air, ice, fog, seawater and surface microlayer in the Bering and Chukchi seas. Mar. Pollut. Bull. 32 (5), 410-419. 
Dawson, D.A., Bantle, J.A., 1987. Development of a reconstituted water medium and preliminary validation of the frog embryo teratogenesis assay-Xenopus (FETAX). J. Appl. Toxicol. 7, 237-244.

De Bleecker, J., Lison, D., Van Den Abeele, K., Willems, J., De Reuck, J., 1994. Acute and subacute organophosphate poisoning in the rat. Neurotoxicology 15 (2), 341-348.

Ellman, G.L., Courtney, K.D., Andres, V., Featherstone, R.M., 1961. A new and rapid colorimetric determination of acetylcholinesterase activity. Biochem. Pharmacol. 7, 8895.

Garbarino, J.R., Snyder-Conn, E., Leiker, T.J., Hoffman, G.L., 2002. Contaminants in artic snow collected over Northwest Alaskan sea ice. Water Air Soil Pollut. 139, 183-214.

Gillilland, C.D., Summer, C.L., Gillilland, M.G., Kannan, K., Villeneuve, D.L., Coady, K.K., Muzzall, P., Mehne, C., Giesy, J.P., 2001. Organochlorine insecticides, polychlorinated biphenyls, and metals in water, sediment, and green frogs from southwestern Michigan. Chemosphere 44 (3), $327-339$.

Gindi, T., Knowland, J., 1979. The activity of cholinesterases during the development of Xenopus laevis. J. Embryol. Exp. Morph. 51, 209-215.

Gupta, R.C., Patterson, G.T., Dettbarn, W.-D., 1987. Biochemical and histochemical alterations following acute soman intoxication in the rat. Toxicol. Appl. Pharmacol. 87, 393-402.

Harris, M.L., Bishop, C.A., Struger, J., Ripley, B., Bogart, J.P., 1998. The functional integrity of northern leopard frog (Rana pipiens) and green frog (Rana clamitans) populations in orchard wetlands. II. Effects of pesticides and eutrophic conditions on early life stage development. Environ. Toxicol. Chem. 17 (7), 1351-1363.

Karen, D.J., Klaine, S.J., Ross, P.E., 2001. Further considerations of the skeletal system as a biomarker of episodic chlorpyrifos exposure. Aquat. Toxicol. 52, 285-296.

Lemus, R., Abdelghani, A., 2000. Chlorpyrifos: an unwelcome pesticide in our homes. Rev. Environ. Health 15, 421433.

Leonard, J.P., Salpeter, M.M., 1979. Agonist-induced myopathy at the neuromuscular junction is mediated by calcium. J. Cell Biol. 82, 811-819.

Lien, N.T.H., Adriaens, D., Janssen, C.R., 1997. Morphological abnormalities in African catfish (Clarias gariepinus) larvae exposed to malathion. Chemosphere 35 (7), 14751486.

Muir, D.C.G., Teixeira, C., Wania, F., 2004. Empirical and modeling evidence of regional atmospheric transport of currently used pesticides. Environ. Toxicol. Chem. 23 (10), 2421-2432.

Ozmen, M., Sener, S., Mete, A., Kucukbay, H., 1999. In vitro and in vivo acetylcholinesterase-inhibiting effect of new classes of organophosphorus compounds. Environ. Toxicol. Chem. 18 (2), 241-246.

Reynolds, E., 1963. The use of lead citrate at high $\mathrm{pH}$ as an electron-opaque stain in electron microscopy. J. Cell Biol. 17, 208-212.

Richards, S.M., Kendall, R.J., 2002. Biochemical effects of chlorpyrifos on two developmental stages of Xenopus laevis. Environ. Toxicol. Chem. 21 (9), 1826-1835.

Richards, S.M., Kendall, R.J., 2003. Physical effects of chlorpyrifos on two stages of Xenopus laevis. J. Toxicol. Environ. Health Part A 66, 75-91.

Sahu, C.R., Ghatak, S., 2002. Effects of dimecron on developing chick embryo: malformations and other histopathological changes. Anat. Histol. Embryol. 31, 15-20.

Seidman, S., Aziz-Aloya, R.B., Timberg, R., Loewenstein, Y., Velan, B., Shafferman, A., Liao, J., Norgaard-Pedersen, B., Brodbeck, U., Soreq, H., 1994. Overexpressed monomeric human acetylcholinesterase induces subtle ultrastructural modifications in developing neuromuscular junctions of Xenopus laevis embryos. J. Neurochem. 62, 1670-1681.

Snawder, J.E., Chambers, J.E., 1989. Toxic and developmental effects of organophosphorus insecticides in embryos of the South African clawed frog. J. Environ. Sci. Health 24 (3), 205-218.

Snawder, J.E., Chambers, J.E., 1990. Critical time periods and the effect of tryptophan in malathion-induced developmental defects in Xenopus embryos. Life Sci. 46, 1635-1642.

Snawder, J.E., Chambers, J.E., 1993. Osteolathyrogenic effects of malathion in Xenopus embryos. Toxicol. Appl. Pharmacol. 121, 210-216.

Spence, H.J., Chen, Y.-J., Winder, S.J., 2002. Muscular dystrophies, the cytoskeleton and cell adhesion. BioEssay 24, 542-552.

Vismara, C., Bernardini, G., Bonfanti, P., Colombo, A., Camatini, M., 1993. The use of in vitro fertilization in the frog embryo teratogenesis assay in Xenopus (FETAX) and its application to ecotoxicology. Sci. Total Environ. (Suppl., Part 1), 787-790.

Wake, D.B., 1991. Declining amphibian populations. Science 253, 860 .

Wecker, L., Mrak, R.E., Dettbarn, W.D., 1986. Evidence of necrosis in human intercostal muscle following inhalation of an organophosphate insecticide. Fundam. Appl. Toxicol. 6, 172-174. 